\title{
The Impact of Risk Management Standards on Patient Safety: The Determinants of MRSA Infections in Acute NHS Hospitals, 2001-2008*
}

\author{
PAUL FENN ${ }^{\dagger}$ \\ DEV VENCAPPA \\ ALASTAIR GRAY \\ OLIVER RIVERO \\ and \\ NEIL RICKMAN
}

\begin{abstract}
We study a key part of NHS policy to ensure high quality health care: failure to supply such care cost the NHS $f 787 \mathrm{~m}$ in clinical negligence payouts during 2009-10. The NHS uses risk management standards to incentivise care and we examine their effects on MRSA infections. Using a specially assembled dataset, our GMM results suggest that improvements in the risk management standards attained by some hospitals are correlated with reductions in their MRSA infection rates. Moreover, the exogeneity of this relationship cannot be rejected for higher risk management levels, suggesting attainment of higher standards was instrumental in reducing infection rates.
\end{abstract}

JEL Classification: I18, K13

Keywords: Risk management, Patient care, Incentives, MRSA

\footnotetext{
* We thank the National Health Service Litigation Authority for kindly permitting access to data. This research formed part of a project entitled 'Public Services: liability, risk pooling and health care quality', which was funded by the ESRC as part of the Public Services Programme, and we are grateful to other participants in that programme for comments on our work.

† Nottingham University Business School, Jubilee Campus, Wollaton Rd, Nottingham NG8 1BB, UK. (email:paul.fenn@nottingham.ac.uk.)

* Nottingham University Business School

$\checkmark$ Health Economics Research Centre, University of Oxford

\# University of Surrey, Erasmus University and CEPR
} 


\section{Introduction}

The cost of compensating victims of injuries caused by their hospital treatment has been a long-standing source of controversy for the NHS. The resources required to recognise the legitimate right of such patients represent a clear opportunity cost to a budget-constrained health system. Recently, this situation has become especially acute, with public spending cuts coinciding with apparent record levels of NHS expenditure on a growing number of compensation claims. ${ }^{1}$ The chair of the NHS Litigation Authority (hereafter NHSLA; the agency tasked with fighting and paying compensation claims) explicitly recognises this trade-off in the foreword to the Authority's 2010 Annual Report: 'A significant and growing proportion of NHS funds, which would otherwise be available for patient care, is being spent on litigation.' In principle, there are many ways to tackle such pressures, ranging from drastic reform of the basis for paying compensation (as proposed by the Chief Medical Officer in 2003: Department of Health, 2003a) to regulating the level of legal fees (as proposed by Jackson, 2009), yet an ongoing role is played by the NHSLA's policies to help contain hospitals' litigation costs. In this paper, we investigate empirically a central element of this policy in order to determine its effectiveness. We do this in the context of a particular patient safety problem, hospital acquired MRSA infections (itself a source of major public concern over the past ten years), and using a unique panel data set we have assembled for this purpose. ${ }^{2}$

The source of the above litigation costs is, of course, tort liability. In principle tort liability is itself a means of incentivising care in the NHS, as hospitals found to have caused injuries through negligent care levels are forced to compensate the patients in question. ${ }^{3}$ However hospitals in

\footnotetext{
1 See for example, "Massive rise in cost to NHS of settling compensation claims" (The Independent, 28 March, 2010). This debate itself can be seen against the background of disquiet about a "compensation culture" in the UK, exemplified by the current Government's setting up of Lord Young's recent examination into this issue (see Young, 2010).

2 The data were collected as part of ESRC grant RES-153-25-0027.

${ }^{3}$ See Danzon (2000) for a survey of theory and empirical results here, and Fenn et al. (2004) for a discussion in the context of the NHS.
} 
England and Wales purchase insurance against the risk of such claims through membership of the NHS's Clinical Negligence Scheme for Trusts (CNST) - a liability risk pool where the NHSLA offers cover in return for contributions from members. ${ }^{4}$ Such membership may have two effects on NHS costs. First, hospitals' contributions may be perceived as excessive by hospital management if not closely linked to their underlying risk levels and this may lead to alternative arrangements being sought by lower risk hospitals, and higher contributions for the remainder. ${ }^{5}$ Second, care levels may be diluted by such insurance so that the volume of claims rises. ${ }^{6}$ In principle, the NHSLA could seek to overcome these problems by setting deductibles (so the hospital internalises a portion of any injury costs it causes), or by experience-rating hospital contributions to the Scheme (so that these contributions rise or fall along with claims history). Since 2001, the NHSLA has withdrawn the use of deductibles, and instead moved towards the use of a form of risk classification (where the NHSLA specifies a direct relationship between the hospital's contribution and verifiable procedures put in place by hospitals to minimise risk). We describe this policy in more detail in Section II but, broadly, hospitals are assessed according to a number of pre-set criteria and classified into one of three standards as a result. Each triggers a contribution discount, with higher standards yielding larger discounts. Future performance is assessed on a regular basis and allows the hospital to apply to be assessed for higher levels over time. A key objective of the current paper is to assess whether hospitals that attain higher standards (as measured by the NHSLA's

\footnotetext{
${ }^{4}$ The CNST is a non-funded, pay-as-you-go risk pool. Membership is not compulsory but in practice all NHS hospitals are members.

5 The NHSLA's Framework Document (para. 2.3.viii) states that one of its key functions is to 'determine contributions from members towards the costs of the contributory schemes'. Clearly, the viability of the scheme would be put at risk if the contributions paid by low risk hospitals were perceived to be excessive.

${ }^{6} \mathrm{~A}$ formal objective is for the NHSLA "to contribute to the improvement of the quality of patient care by providing incentives within the schemes for NHS bodies to improve cost effective clinical and non clinical risk management" (NHSLA Framework Document, para. 2.2.v).
} 
criteria) are associated with improved levels of patient safety (as measured by MRSA infection rates). ${ }^{7}$

The presence of such an association may be a necessary condition for an effective risk management system but it does not indicate how the system achieves this. In common with other insurance settings, two broad possibilities exist. First, the policy of offering financial discounts for risk management standards is consistent with a motivation to reduce moral hazard through incentivising hospitals to invest in improved risk management processes (Bond and Crocker, 1991). Second, it could alternatively be argued that the NHSLA is using the risk management standards as a way of classifying those hospitals into groups which, on actuarial grounds, would merit differing contributions due to differing expected claims costs (Crocker and Snow, 1986; 2000). These two alternative views of risk classification are difficult to distinguish empirically: any relationship found in cross-sectional data (conditional on observables) showing that hospitals with good safety outcomes are those with better risk management standards (and hence with lower contributions) would be consistent with either explanation. However, as Chiappori (2000) observes, providing dynamic data are available on safety outcomes and premiums (or risk management discounts in our case), a distinction may be empirically testable and this is the approach we adopt. ${ }^{8}$ In particular, we test for exogeneity of the levels of risk management standards achieved by hospitals as this provides an indication of whether this achievement reflected prior care levels, or induced additional investment in care. $\quad$ To the extent that these levels are exogenous to the patient care provided, this suggests a causal relationship running from risk management standard to care and, in turn, this is consistent with incentives offered by the

${ }^{7}$ Fenn et al. (2007) and Fenn et al. (2010) undertake a similar analysis of the NHSLA's previous use of deductibles.

${ }^{8}$ See also Abbring, Chiappori and Pinquet (2003) and Abbring, Chiappori, Heckman and Pinquet (2003).

9 Chiappori (2000, p. 373) favours this approach in his discussion of empirical research in other insurance settings. 
NHSLA (risk management discounts) helping to encourage patient care, ceteris paribus.

In order to examine the effects of these policies on hospital care, we need a proxy for care. We use MRSA infection rates within NHS hospitals. ${ }^{10}$ Hospital-acquired infections such as methicillin resistant staphylococcus aureus (MRSA) have become an especially important policy concern in the NHS over the last twenty years. A dramatic increase in the proportion of S. aureus bacteraemia that were resistant to penicillin treatment occurred in the 1990s, from $2 \%$ in 1990 to a peak of $43 \%$ in 2002 (Johnson et al. 2005). Some of these cases, particularly in very young and elderly patients, had severe consequences, with the Office for National Statistics reporting that MRSA was mentioned on 1,629 death certificates in England and Wales in 2005. Well-documented compensation payouts to a number of MRSA sufferers, additional treatment costs of approximately $£ 1$ bn per year (National Audit Office, 2000) and reputation costs to the NHS itself have made hospitalacquired infections a high profile and important focus for the patient safety debate in the NHS, and led to the introduction of a mandatory surveillance system in England in 2001 (Health Protection Agency, 2007). Better surveillance, enhanced hospital cleaning measures, financial incentives and penalties, and education and publicity campaigns have since been accompanied by a substantial decrease in reported cases: a total of 2,935 cases of MRSA infections in England were reported to the Health Protection Agency in the year ending March 2009, down from a peak of 7,700 in 2003/04.

This decrease has occurred in spite of a substantial increase in hospital activity in the form of increased inpatient admissions, particularly of elderly patients and those with health seriously compromised by underlying disease. The implication seems to be that the reduction in MRSA infections has been achieved in the face of increased patient exposure and must therefore be

\footnotetext{
${ }^{10}$ MRSA rates may provide a suitable subject for such analysis because they are linked to hospital-wide activity as opposed to the particular treatment needs of an individual patient; as such they could be more amenable to 'control' by management initiatives.
} 
attributable to measures taken by NHS trusts to reduce risk, several of which have involved multi-million pound expenditure campaigns (as documented in Section II). In fact, other trends over the period may also have affected the incidence of MRSA infections. ${ }^{11}$ Notwithstanding this point, a potential concern with many of the measures adopted to address MRSA infections is that they have tended to exhort rather than incentivise improved behaviour and, in the case of one-off expenditure drives, may not have a lasting impact an especially acute problem given the limited prospects for repetition in the current public expenditure climate. This means that more 'ongoing' policies such as providing financial incentives to comply with the NHSLA's risk management standards may form an important component of longer term attempts to control MRSA infection rates.

In order to assess the effects of risk management standards on MRSA infection rates, while seeking to control for other relevant trends and policy measures, we use panel data on NHS acute hospital trusts from several previously unconnected administrative databases. The panel covers the period 2001-8; i.e. it starts when the NHSLA moved to exclusive use of risk management standards, and it encompasses the rise and decline of MRSA rates in the NHS. We are able to control for various observable measures of hospital risk type, including mean length of stay, bed utilisation, and casemix. Each of these measures varies across hospitals and over time and, as we have seen, may also provide part of the explanation for MRSA reductions. ${ }^{12}$ There are other potentially relevant time-independent variables such as the geographical location of the hospital, and the specialist status of the hospital, and we also explore these. We use time dummies in order to control for specific policy measures (including separate ones for the period covered by the

\footnotetext{
11 These include the shift towards shorter lengths of stay in acute hospitals (Lucet et al., 2005), and changes to the utilisation of capacity (Borg, 2003; Cunningham et al., 2006). In addition, other factors will clearly determine the observed variations in infection rates across hospitals: the type of hospital and its specialty casemix, as well as staffing issues and location.

12 It could be argued that an endogeneity problem exists insofar as MRSA infections may influence average length of stay: However, MRSA infections are a tiny proportion of all hospital cases - in 2007-8 the maximum number in any hospital was 24.6 per 100,000 beddays - and hence have an undetectable effect on hospital average length of stay.
} 
Health Act and the 'deep clean' initiative). Crucially, in order to assess the effectiveness of the NHSLA's risk classification measures, we use information on the level of risk management achieved by each hospital (as assessed by the NHSLA) in each year of our period. In addition, the dynamic nature of the panel offers the possibility of testing for exogeneity of the risk management standards. This is the first time these various pieces of information have been brought together and we believe they provide the best opportunity yet to assess the effects of financial incentives on patient safety and litigation cost control within the NHS.

Our paper contributes to several academic debates. First, the role of financial incentives in stimulating care has been a long-standing interest to economists in settings ranging from the workplace (Workers' Compensation $^{13}$ ), the road (accident liability ${ }^{14}$ ) and health care ${ }^{15}$, with many countries running largescale compensation programmes in these areas: it is essential that these programmes are able to incentivise the agents they cover to take care and to reveal their risk class in order to ensure actuarially fair contribution from members. From a more general perspective, the effectiveness of financial incentives goes to the heart of principal-agent models. Second, we provide a relatively rare study of the empirical operation of risk classification (as opposed to the use of deductibles), which is of great importance to some largescale compensation programmes like the US workers compensation scheme - as well as the NHS. Third, as stated above, we feel that our data provide an opportunity to examine whether the NHSLA's risk classification reflects hospital heterogeneity or incentivises patient safety measures and thus contributes to an important literature on the presence of moral hazard or adverse selection in insurance settings.

The paper is structured as follows. Section II presents an overview of the risk management measures used by NHS hospitals with respect to their

\footnotetext{
${ }^{13}$ See e.g. Moore and Viscusi (1990).

${ }^{14}$ See e.g. Kochanowski and Young (1985); Devlin (1992); Cummins et al. (2001).

${ }^{15}$ See e.g. Kessler and McClennan (1996, 2002), Danzon (2000); Fenn et al. (2004), Sloan and Chepke (2008).
} 
exposure to hospital-acquired infections. These measures include both direct cleaning initiatives and the indirect financial incentives rewarding good risk management practices through discounts to CNST contributions. Section III reviews our panel dataset, and the following section outlines the estimation methodologies by which we analyse this dataset to test hypotheses concerning the determinants of the frequency of MRSA infections across hospitals and over time. Section V presents our results and a final section concludes.

\section{NHS risk management and MRSA}

\section{Liability risk pooling and risk management standards}

Hospitals naturally seek protection from the liabilities they may face under tort. Insurance provides such protection but information asymmetries can leave the insurer exposed to moral hazard by removing hospitals' exposure to the costs of their actions, and to the danger of rising premiums as a result of adverse selection. ${ }^{16}$ We now describe the current arrangements for protecting against these problems in the NHS. The main body responsible for administering schemes allowing NHS trusts in England to pool the costs of liabilities to patients arising from the carrying out of their functions is the NHS Litigation Authority (NHSLA), a Special Health Authority established in November 1995. The NHSLA is responsible for administering the Clinical Negligence Scheme for Trusts (CNST), a voluntary scheme to which all English NHS Trusts and PCTs currently belong, and covers clinical incidents occurring on or after the date when the Trust joined the scheme.

The current CNST scheme is a 'pay as you go' scheme, in which contributions for each year are calculated so as to cover expected costs, including claims and administrative costs. The pay as you go approach minimises the cash reserves that are required to operate the scheme (by

\footnotetext{
16 We have noted above that membership of the CNST is not compulsory. Consequently, as NHS hospitals trusts gain more financial autonomy, there is a risk that commercial liability insurers could offer preferential terms to low risk hospitals, hence endangering the viability of the CNST through a form of adverse selection that would place upward pressure on contributions.
} 
comparison with fully funded liability insurance). The basis of the scheme is an actuarial model that forecasts the expenditure based on the predicted number and value of claims arising in each period. If contributions are set at a level that exceeds the outturn expenditure, these are passed back to members in the form of rebates on contributions in future years.

Having estimated the aggregate contributions required to finance the scheme, individual contributions from each scheme member are calculated. Contributions are based on the number of staff employed in different risk categories by each Trust member. Whole time equivalent (W'TE) staff are counted and then divided into five risk categories, reflecting the national experience of claims rates and values by specialty: low risk, medium risk, high risk, very high risk, and obstetrics \& gynaecology. Weightings are attached to each of these, on the basis of the predicted number and value of claims in each category, and the weights are given a cash value that will equate the total contributions required from all members times the total staff employed by all members. It is then possible to calculate the annual contribution required from each member.

Two adjustments are then made to this estimated contribution. ${ }^{17}$ First, each Trust is experience rated on the basis of actual compared with expected claims based on risk exposure measured using the WTE staff data. The experience rating takes one of five values: $+10 \%,+5 \%, 0 \%,-5 \%$ and $-10 \%$. Second, and most importantly for this paper, the scheme also gives a role to the risk management processes that members have in place when determining contributions. Assessments are currently routinely conducted every two years, but organisations failing to attain the first level of standard are assessed annually. The assessment is based on seven 'core' standards, amongst which are specific reference to infection control measures. ${ }^{18}$ Trusts which are assessed as complying with the standards are entitled to a discount from their

\footnotetext{
17 In addition, until 2002, hospitals were permitted to choose deductibles levels below which they were responsible for the patient's claim, and which in turn affected the contribution paid. This facility no longer exists.

18 This includes explicit reference to directly related practices such as measures in place to ensure hand hygiene amongst patients and staff (see NHSLA, 2010).
} 
scheme contribution for the following two financial years. The discounts on CNST contributions are 10\% (level 1 compliance), 20\% (level 2 compliance) and 30\% (level 3 compliance). The discount earned by members is applied to contributions in the financial year following a successful assessment and is valid for 2 years. ${ }^{19}$

\section{Other measures to control MRSA infections}

In 2001 a mandatory surveillance system was introduced in England, in order to provide better information on the number, characteristics and distribution of MRSA infections; this scheme has since been widened and strengthened, for example since 2005 to provide specialty information and data on whether infection was present at admission (Health Protection Agency, 2007). Following this, in 2002 a broad control strategy for all infectious diseases was set out, which recommended a wide set of policy initiatives including strengthened control measures for health care associated infections (Department of Health, 2002). In 2003 the Chief Medical Officer published a report focusing on healthcare associated infection, giving local NHS agencies specific directions on actions that should be taken to reduce healthcare associated infections. These included better surveillance, improved techniques for use of catheters, tubes and instruments, higher standards of hygiene in clinical practice, more prudent use of antibiotics, and a range of managerial and organisational changes such as having designated Directors of Infection Prevention and Control within each local NHS organisation, instructing infection control teams to work directly with bed managers, and reminding Chief Executives of NHS organisations of their legal duties to identify and control infection risk in the workplace (Department of Health, 2003b).

In 2004 a number of specific steps were taken to implement these recommendations. The "cleanyourhands" campaign was launched by the NPSA as a national multimodal advertising initiative in England and Wales to

\footnotetext{
19 A typical large teaching hospital could have a total CNST contribution of approximately $f_{10 \mathrm{~m}}$ in 2009-10; the value of a level 3 discount for such trusts could therefore be in the region of $f, 3 \mathrm{~m}$ per annum.
} 
improve hand hygiene amongst healthcare workers, particularly in acute hospitals, by means of much higher usage of alcohol handrubs and soaps. Also in 2004, the Department of Health began to direct additional resources towards NHS trusts with particularly high MRSA rates.

In 2006 a new Health Act was introduced, setting out a detailed hygiene code for NHS organisations to assess and manage infection risks, implement clinical care protocols, and provide training: adhering to this is a statutory requirement on all NHS organisations (Department of Health, 2006) and failure to comply could potentially result in civil or criminal proceedings against individual members of the hospital management. This was followed in 2007 by an agreement by all strategic health authorities to spend a total of f57 million by the end of 2007-8 on 'deep cleaning' all hospitals, involving wards being vacated and cleaned by steam cleaners using detergent and water at high temperatures. These and several other policy initiatives are summarised in 'Clean, safe care: reducing infections and saving lives' (Department of Health, 2008).

Taken together, therefore, the period since 2000 has witnessed a large number of policy initiatives and managerial changes relating to healthcare associated infection. It is possible that these had some effect on the incidence of MRSA and other health associated infections, but there is little reliable evidence on this. Thus, in the process of controlling for these initiatives, our paper provides a rare opportunity to help assess them.

\section{Data}

The data used for this project were accessed from various sources made available by the Department of Health $(\mathrm{DoH})$ and the NHSLA. ${ }^{20}$ The variables used were aggregated to trust level wherever necessary, and a panel dataset created. As the DoH and NHSLA use different administrative codes for identifying hospital trusts, it was necessary to match manually the records from the hospital trust names when merging them together. The names of the

\footnotetext{
${ }^{20}$ Appendix 1 details the sources of our data.
} 
trusts were not always recorded consistently across the different data sources and the data matching process involved the use of a search and replace algorithm combined with manual identification of the names in some cases. For consistency, we used the DoH administrative codes and updated these as and when data sets relevant to the analysis were added. Since all the variables used in this study could not be observed for all the tracked hospital trusts in all years, we ended up with an unbalanced panel data set over the period 2001 to 2008 .

\section{Risk management standards}

As explained above, the payment for CNST membership varies depending on the hospital's casemix, the claims experience, and the risk management standards applied. Hospitals with low assessed risk management standards face a higher CNST contribution than those with high standards. ${ }^{21}$ Moreover, these standards have been assessed and re-assessed by the NHSLA over time. Hospitals have a clear financial incentive to improve their procedures via the risk management discounts which are applied (the moral hazard argument) or, alternatively, those hospitals with good procedures in place have a clear incentive to demonstrate that they are entitled to the reduced contribution. The availability of panel data creates an opportunity to test whether or not this incentive led to improvements in hospital cleanliness which resulted in better control over hospital-borne infections.

Table 1 shows the variation in assessed risk management standards across acute NHS hospital trusts from 2001-8. It is evident that the trend over time has been for an overall progressive increase in the number of hospitals assessed as having high standards of risk management, although considerable variations across hospitals remain throughout the period of observation.

*** Tables 1 and 2 here

${ }^{21} 10 \%$ discount for attaining level 1, 20\% for level 2, 30\% for level 3 . 
Table 2 shows the variation in MRSA infection rates across hospitals attaining these different risk management levels. There does seem to be a clear association in the pooled data such that higher risk management levels are associated with lower infection rates. However, there are many possibilities for hospital characteristics to vary across risk management levels in a way which would affect their infection rates, so the multivariate analysis undertaken below is essential before arriving at firm conclusions.

Moreover, a fundamental issue for the subsequent analysis of these data is the potential endogeneity of the risk management standard. As suggested above, hospitals with good prior safety records (including low infection rates) would be more likely to apply for and be awarded a contribution discount by the NHSLA at audit - that is, the standards would be endogenous. If by contrast the contribution discount incentivises investment in patient safety measures such as better infection control, then the attainment of higher risk management standards would be followed by reduced infection rates - that is, the standards would be exogenous. We therefore allow for both possibilities in the estimates reported below.

\section{MRSA infections, casemix and hospital activity}

Data on MRSA infections were extracted from the Health Protection Agency Communicable Disease Surveillance Centre. These cover the period from April 2001 (when mandatory surveillance began) to September 2009. Data were available for each acute NHS hospital trust by number of MRSA bacteraemia reports.

Figure 1 presents the total MRSA bacteraemia reports per year in acute NHS hospital trusts, and the rate per 10,000 Finished Consultant Episodes (FCEs). There appears to be a steady decline in total infections since 2003, accelerating sharply after 2006. The MRSA infection rate fell from 5.86 reports per 10,000 FCEs in 2001 to 1.83 per 10,000 FCEs in 2008, representing an overall reduction of $69 \%$ over that period.

\footnotetext{
$* * *$ Figure 1 here $* * *$
} 
Figure 2 shows how the annual number of MRSA infections per hospital were distributed across acute NHS hospitals. Clearly, there are considerable differences in the number of infections across hospitals, which will be determined by hospital throughput and casemix, but which may, of course, also be a function of the infection control measures discussed above as well as external factors influencing the incidence rate. It should be noted that there are a relatively small number of hospitals for which there were zero infections observed in a given year. ${ }^{22}$

\section{*** Figure 2 here $* * *$}

Figure 3 shows the regional breakdown of MRSA infection rates per 10,000 FCEs. There appears to be a higher incidence in London than in other regions, but this may of course be due to variations in casemix, length of stay and rates of bed utilisation in London hospitals.

\section{*** Figure 3 here $* * *$}

The most important factors potentially influencing inter-hospital variations in MRSA infections relate to the throughput, length of stay, capacity utilisation and casemix of the hospital - direct measures of exposure to infection. Clearly, raw activity level measures such as the number of admissions or treatment episodes at a particular hospital will be the main factor determining the number of infections. In addition, the nature of the treatment episodes will influence the frequency of infection: hospitals with a large proportion of surgical patients may be more open to infection than others, for instance. Table 3 summarises the panel of data we have in relation to hospital activity levels (measured by the total number of finished consultant

\footnotetext{
${ }^{22}$ In fact, only one hospital reported zero infections in all eight years of observation, implying that all but one hospital contributed a positive observation to the panel dataset.
} 
episodes and average length of stay), bed utilisation rates (i.e. occupied beds relative to bed capacity), and casemix variables (i.e. the proportion of bed days allocated to the main treatment specialities).

\section{*** Table 3 here $* * *$}

Figures 4 and 5 show the regional patterns of mean length of stay and bed utilisation rates respectively. The pattern of change in relation to mean length of stay looks to be highly correlated with changes in MRSA rates; on the whole, regions such as London, with high but rapidly declining MRSA rates, also have high but rapidly declining length of stay. By contrast, while the regions with the highest bed utilisation rates (London and the South East) also have relatively high MRSA rates, the correspondence is not so marked.

\section{*** Figures 4 and 5 here $* * *$}

Finally, we also have data on the expenditure by NHS acute hospitals on cleaning services, using compulsory returns to the NHS Information Centre since 1999 on Hospital Estates and Facilities Statistics. This expenditure showed a significant increase in relation to the volume of activity (i.e. patient bed-days). Table 4 summarises:

\section{*** Table 4 here ***}

\section{Estimation}

\section{Data generation process}

The observed total number of MRSA infections in a given hospital $i$ would clearly depend on a measure of patients' exposure to risk - that is, the number of treatment episodes for the hospital in a given year $\left(T_{i t}\right)$. Consequently, the expected number of infections in year $t$ at hospital $i$ would be $T_{i t} \pi_{i t}$ where $\pi_{i t}$ represents the mean probability of a patient becoming infected during a given 
treatment episode.

The latent variable $\pi_{i t}$ can be modelled as a function of observed covariates and unobserved random variables. With a conventional loglinear specification of this function, we have

$$
\pi_{i t}=\exp \left(\boldsymbol{\beta}_{1} \varrho_{i t}+\beta_{2} d_{i t}+\varepsilon_{i t}\right)
$$

where $\rho_{i t}$ is a vector of measures capturing the hospital's location, casemix and activity rates (length of stay, bed utilisation rate). The variable $d_{i t}$ measures the risk management standard achieved by the hospital and; $\boldsymbol{\beta}_{1}$ and $\beta_{2}$ are the associated coefficients. The error term $\varepsilon_{i t}$ measures the impact of unobserved heterogeneity in the underlying risk across hospitals: given the difficulty in capturing through observables all variations in case complexity, management efficiency, and other local factors, this is likely to be a significant determinant of inter-hospital variation in the number of infections.

If the observed number of infections in hospital $i$ in year $t$ is represented by $\chi_{i}$, then we can construct an estimating equation for (1) as:

$$
\frac{x_{i t}}{T_{i t}}=\exp \left(\beta_{1} \varrho_{i t}+\beta_{2} d_{i t}+u_{i}+v_{i t}\right)
$$

where the LHS variable in (2) is the infection rate - the number of observed infections as a proportion of the number of treatment episodes. ${ }^{23}$ Furthermore, if $x_{i t}$ is strictly positive (as with almost all our data), equation (2) can be transformed for estimation as

$$
\ln \left(\frac{x_{i t}}{T_{i t}}\right)=\beta_{1} \varrho_{i t}+\beta_{2} d_{i t}+u_{i}+v_{i t}
$$

\footnotetext{
${ }^{23}$ Note that this variable could in principle be greater than 1 , as each treatment episode could be characterised by more than one infection - that is, it is a rate, not a probability. It is for this reason that we do not choose to estimate eq. (2) using a probit estimator.
} 
Our observation period in this study is the years from 2001 to 2008. Clearly during this period there may also have been a systematic change over time in the incidence of MRSA bacteraemia due to direct measures taken by the NHSA to control infection rates, and for this reason we include time dummy variables in all our regressions. In addition, however, it is possible that there is a degree of persistence in the reported rate of infection within a given hospital, due perhaps to the delays in organising appropriate responses on the part of hospital management. The appropriate estimating equation will therefore have a lagged dependent variable as one of the regressors. In the case of the loglinear version of the data generating process, we have:

$$
\ln \left(\frac{x_{i t}}{T_{i t}}\right)=\alpha \ln \left(\frac{x_{i t-1}}{T_{i t-1}}\right)+\beta_{1} \varrho_{i t}+\beta_{2} d_{i t}+u_{i}+v_{i t}
$$

where the parameter $\alpha$ measures the degree of persistence.

An important issue for estimation arises from the possibility that $d$ is an endogenous regressor due to the possibility that past levels of expenditure on risk management activities (including infection control measures) help determine the standard applied for and achieved. If we can further assume that $\mathrm{E}\left[\ln \left(\varepsilon_{i t}\right) \mid \mathbf{z}\right]$ is a constant independent of an instrumental variable vector $\mathbf{z}$, then even where $d$ is shown to be endogenous it is possible to estimate consistently the parameters of the log-linear model in (4) using a dynamic GMM estimator which is fully robust and asymptotically efficient (Baum et al., 2003). In estimating (4) we have an additional source of endogeneity bias through the presence of the lagged dependent variable ('dynamic panel bias'). Moreover, in this case the standard fixed-effect estimator is unable to solve this problem using higher lags of the dependent variable as instruments. The usual solution to this problem is to resort to the use of first differencing of the data, and then to estimate the resulting equation using GMM (Arellano and Bond, 1991). The (differenced) lagged dependent variable remains endogenous, but now it is possible to use the lagged levels of the dependent variable as instruments. However, in circumstances where there is stochastic 
variation in the dependent variable around a relatively stable trend, it has been shown that difference GMM lacks efficiency because in that case lagged levels convey little information about future changes (Blundell and Bond, 1998). Drawing on Arellano and Bover (1995), Blundell and Bond show that an alternative is to estimate (4) as an untransformed equation in levels, using the differences in the lagged dependent variable as instruments. These differenced instruments are exogenous providing that they are uncorrelated with the fixed effects $u_{i}{ }^{24}$ They can be added to the instruments in levels from the difference GMM estimator to form a potentially more efficient system GMM estimator (Blundell and Bond, 1998).

In addition to providing a means of estimating the coefficient on the endogenous lagged dependent variable consistently, the dynamic system GMM estimator also allows for the possibility of endogeneity in other regressors through the use of lagged instruments. A pairwise comparison of sets of orthogonality conditions corresponding to the assumption of endogeneity or exogeneity respectively can be undertaken, with the difference in Hansen $\mathrm{J}$ test statistics obtained from these comparisons being distributed as Chi-squared with degrees of freedom equal to the number of regressors being tested for endogeneity. Rejection of the null implies that the regressor (or subset of regressors) should be treated as endogenous. ${ }^{25}$

As well as ensuring an appropriate estimation strategy, controlling for possible endogeneity of the risk management standards may also provide insights into the way that the standards operate - as discussed in the Introduction. In particular, by indicating whether patient safety outcomes 'lead' or 'lag' attainment of a given standard, we can comment on whether they address problems associated with the classification of hospital risk or incentives to reduce it that are faced by the NHSLA.

\footnotetext{
${ }^{24}$ It can be shown that, under certain assumptions, this requirement is equivalent to one about the initial conditions of the data generating process (Blundell and Bond, 1998).

${ }^{25}$ Baum et al. (2003, pp. 23-24) show the equivalence of this "difference in Hansen" test to the conventional Durbin-Wu-Hausman endogeneity test.
} 


\section{Results}

Table 5 shows the results for the system GMM model used to estimate the determinants of inter-hospital variations in MRSA rates over time. The lagged dependent variable is assumed to be endogenous, as are cleaning costs. ${ }^{26}$ Moreover, because of the ambiguity over the role of risk management standards discussed above, we test for the joint endogeneity of these regressors using a difference in Hansen test as explained above (the result of the difference in Hansen test is reported at the foot of the Table). We use as instruments the observed overall claims experience of the hospital, as reported by the NHSLA, as well as second and higher lags of the potentially endogenous variables. ${ }^{27}$ All other variables are assumed to be strictly exogenous, and are therefore instrumented by their contemporaneous and lagged values. The overall validity of the instrument set is assessed by means of a robust Hansen J statistic which does not reject the null that the full instrument sets are exogenous.

The table shows a significant coefficient on the lagged dependent variable with a value 0.172 , indicating a degree of persistence in the infection rates, and confirming the need for a dynamic model. Moreover the diagnostic tests with respect to autocorrelation are satisfactory: as expected, the null of no first order serial correlation in the differenced disturbances can be rejected, but the null of no second order serial correlation cannot ${ }^{28}$.

\section{*** Table 5 here $* * *$}

\footnotetext{
26 It seems likely that cleaning campaigns would be directed at those hospitals with higher infection rates.

27 The claims experience of the hospital is the only available candidate for an external instrument; it would seem on a priori grounds to be a factor which may be correlated with the choice of risk management standard, but, given the wide variety of factors in addition to MRSA infections that may lead to a negligence claim, it is unlikely to be correlated with the error term. All other instruments used are internal to the model. As explained in the text, we test for overall instrument validity using Hansen J tests.

28 Clearly, serial correlation of the error terms might be present due to model misspecification. The test for second order autocorrelation in the first differenced error terms can be considered to be a test for first order autocorrelation of the undifferenced error terms; our results suggest that the null of no second order autocorrelation in the first differences cannot be rejected.
} 


\section{Risk management standards}

From Table 5, the coefficients on attainment of CNST levels 2 and 3 are both negative; in the case of level 3 the coefficient is statistically significant, showing a reduction in the infection rate for these hospitals of $23 \% .{ }^{29}$ In the case of level 2, the effect is equivalent to a reduction of $9 \%$, though this fails to reach conventional levels of significance. In order to interpret these results in the light of the discussion earlier in this paper, we test the risk management levels for endogeneity, using the difference in Hansen test described above. The results show that the null of exogeneity cannot be rejected.

These results suggest that the incentive properties of the discounts available for attaining higher risk management levels are non-negligible. Hospitals achieving level 3, in particular, appear to have been incentivised by the higher discount available to invest in new procedures, the outcome of which does seem to be improved patient safety, at least as measured by reductions in MRSA infection rates. This causality suggests that the dominant factor operating on level 3 is the incentivisation of additional investment in risk management as described by Bond and Crocker (1991). At least some of the improvements in infection rates associated with the NHSLA's risk classification can therefore be said to result directly from the financial incentives provided within the CNST scheme.

\section{Hospital hygiene measures}

Our measure of cleaning costs per bedday was designed partly to measure the extent to which differences across hospitals in cleaning effort impacted on infection rates, but also to pick up the timing and intensity of the "deep clean" initiatives as they affected individual hospitals. The results of the regression reported in Table 5 indicate, perhaps surprisingly, that the intensity of cleaning

\footnotetext{
29 Note that the coefficients on binary regressors in a loglinear model need careful interpretation; the percentage changes reported here are derived from the coefficients in Table 5, transformed using the method suggested by Kennedy (1981). Note also that the effects reported above are short term effects; because the dynamic specification is supported here, the long term effects will be greater.
} 
was not a factor explaining differences in infection rates across hospitals over time. It is likely that hospital hygiene is a much broader issue than can be measured by cleaning effort.

The time dummies included in our regression specification are there to pick up the effect of other systematic factors changing over time which are not captured by changes in length of stay, casemix, risk management standards, cleaning effort or other observables. In each case the coefficients on these dummies are testing the hypothesis that infection rates had changed over time, after controlling for other observable factors. Although they are all negative from 2002, it is not until 2007 that a statistically significant effect is found, with the results for that year showing a highly significant reduction of approximately $30 \%$ in the MRSA infection rate by comparison with 2006, and for 2008 a further significant reduction of approximately $20 \%$ by comparison with 2007. This 'unexplained' part of the fall in the infection rate could of course be due to underlying changes in the prevalence of MRSA in the community, but on grounds of timing it seems most likely to be due to the range of actions taken by management following the Health Act 2006 which made hospital hygeine a statutory requirement (see the discussion in Section II above). There is, however, no evidence that the earlier measures based on exhortations, such as the 'cleanyourhands' campaign, had any significant effect on the overall MRSA infection rate.

\section{Length of stay and bed utilisation}

The estimates also show a strong sensitivity of the infection rates to the average length of stay in acute NHS trusts. The estimated elasticity of 0.551 is statistically significant, implying that acute hospitals with longer mean lengths of stay will have increased MRSA rates, although not fully in proportion to the differentials in length of stay. This suggests that the changes in average acute lengths of stay observed nationally (see Figure 3 and Table 4) should have had a significant effect on infection rates, with each percentage point reduction in length of stay resulting in a 0.55 percentage point reduction in infection rates. 
This implies that of the $69 \%$ reduction in the MRSA infection rate in acute hospitals observed nationally between 2001 and 2008, approximately 19\% was due to the trend towards lower duration of acute hospital stays. From Table 2, the fall in mean length of stay nationally from 3.585 in 2001 to 2.436 in 2008 represents a decline of $32 \%$, implying a $19 \%$ reduction in MRSA rates attributable to this factor. Indeed, much of the fall in MRSA rates before 2006 could be explained purely in terms of the length of stay effect.

Our results provide no evidence of an effect of bed utilisation on infection rates. In particular, it seems that hospitals in certain areas of the country have both high bed utilisation rates and relatively high MRSA rates, but that when we control for location, this correlation disappears. The regions which do seem to have high incidence rates of MRSA infections after controlling for other factors are London, the South East and, particularly, the West Midlands. This may have something to do with the comparative demographics of these regions, but clearly more research is needed on this.

\section{Casemix and hospital type}

Turning finally to the results on casemix, there seems to be evidence that MRSA infection rates are highest when there is a high proportion of other surgery bed-days. MRSA infection rates also vary according to hospital type: single-specialty hospitals have much lower MRSA infection rates than others, even after controlling for casemix and length of stay. The coefficient estimate on the dummy variable for single specialty hospitals suggests that the infection rates in these hospitals is less than half that in other acute hospitals, after controlling for casemix and length of stay. This finding may be consistent with Grundmann et al.'s (2010) recent evidence that MRSA infections are spread through movement of patients within the hospital system, rather than in the community. 


\section{Conclusion}

In this paper we have used a dynamic panel data specification to explore the determinants of variations in the rate of reported MRSA infections across acute NHS hospitals over the period 2001-2008, with particular emphasis on the impact of financial incentives to improve risk management. This issue is central to debates about the costs of compensation claims against the NHS and how this impacts on the (increasingly) scarce resources available for health care. This was a period during which the NHSLA had abandoned the conventional use of deductibles as a means of incentivising hospital management to improve patient safety measures. The alternative approach implemented a process of continuous audit of risk management procedures in order to reward 'good' hospitals with lower contributions to the compensation scheme. This approach depends on hospital management being incentivised by the lower contributions to invest in better procedures designed to improve patient safety through the adoption of improved risk managements standards.

Clearly the success of this strategy relies on a comparison of the benefits from reduced contributions against the compliance costs required. Our findings indicate that the higher discount levels associated with attainment of level 3 were sufficient to justify empirically detectable improvements in infection control by some hospitals, but the lower discounts available for level 2 compliance were less effective in terms of improvements in care. This association between risk management standards and patient safety could of course be a simple outcome of risk-related contributions. However, we have found no evidence to dispute the exogeneity of these standards, which is consistent with the existence of a causal relationship between an improvement in standards and a subsequent improvement in patient safety. This finding therefore supports the view expressed by Bond and Crocker (1991) that risk classification by insurers based on observable investments can be used as a means of minimising moral hazard. Although not tested here, a strong inference could be made that hospitals with 
measurable improvements in patient safety will be those with reduced liabilities in terms of patient compensation.

In addition to the effect of risk management standards, we have also tested for the relationship between mean length of stay, bed utilisation, and casemix measures on MRSA infection rates. Our findings are consistent with a fall in the rate of MRSA infections, due in part to the trend reduction in average length of stay in NHS acute hospitals (indeed our results suggest that the major part of the overall reduction prior to 2007 was due to the fall in average length of stay). It could be argued that our finding of a significant elasticity of MRSA rates with respect to average length of stay is evidence that MRSA is typically acquired within the hospital, rather than acquired in the community and discovered in the hospital. ${ }^{30}$

There remains a significant unexplained part of the variation in infection rates over time which may be attributable to government action in relation to patient safety measures. On grounds of timing in relation to this residual pattern, it is possible to argue that the Health Act of 2006, which made hospital hygeine a statutory requirement, was highly effective. It is less convincing to argue from our evidence that the various directions made by the Chief Medical Officer in 2003 and implemented from 2004 onwards were a factor leading to lower infection rates.

Our results may have useful implications for policy makers and the wider literature. At a time when patient safety and subsequent claims for compensation are high on the policy agenda, the results indicate that financial incentives linked to risk classification can play an important role in this area. In particular, they suggest that risk management standards can be an effective part of the NHSLA's arsenal. This may be equally relevant to other largescale compensation settings where it is difficult for the insurer to identify and manage incentives at a more micro level, such as US-style Workers' Compensation schemes.

\footnotetext{
${ }^{30}$ See Grundmann et al. (2010).
} 
As always, the interpretation (and the detail) of findings need to be revisited as new data become available. We feel that the dynamic panel we have assembled can play a useful role here and we plan to update and revisit it over time. It would also be interesting to explore the possible reasons for the stronger results we have found for level 3 risk management standards: perhaps they require more 'intense' efforts in some sense than their lower counterparts. ${ }^{31}$ In the meantime, the effective means of control of patient safety and health care resources will continue to be an important topic for the NHS - and for other health care systems around the world.

31 One possibility would be to construct a continuous measure of hospitals' costs of achieving each standard in order to capture effort intensity. We are not aware that such data are currently available. 


\section{References}

Abbring, J., Chiappori, P-A., Heckman, J. and Pinquet, J. (2003). 'Adverse selection and moral hazard in insurance: Can dynamic data help to distinguish?', Department. of Economics, University of Chicago.

Abbring, J., Chiappori, P-A. and Pinquet, J. (2003). 'Moral hazard and dynamic insurance data', Journal of the European Economic Association, Vol. 1, pp. 767-820.

Arellano, M. and Bond, S. (1991). 'Some tests of specification for panel data: Monte Carlo evidence and an application to employment equations', Review of Economic Studies, Vol. 58, pp. 277-297.

Arellano, M. and Bover, O. (1995). 'Another look at the instrumental variable estimation of error-components models', Journal of Econometrics, Vol. 68, pp. 29-51.

Baum, C., Shaffer M. and Stillman, S. (2003). 'Instrumental variables and GMM: estimation and testing', Working Paper No. 545, Department of Economics, Boston College.

Blundell, R. and Bond, S. (1998). 'Initial conditions and moment restrictions in dynamic panel data models', Journal of Econometrics, Vol. 87, pp. 115-143.

Bond, E. and Crocker, K. (1991). 'Smoking, skydiving, and knitting: The endogenous categorization of risks in insurance markets with asymmetric information', Journal of Political Economy, Vol. 99, pp. 177-200.

Borg, M. (2003). 'Bed occupancy and overcrowding as determinant factors in the incidence of MRSA infections within general ward settings', Journal of Hospital Infection, Vol. 54, pp. 316-318.

Chiappori, P-A. (2000). 'Econometric models of insurance under asymmetric information', in Dionne, G. (ed.) Handbook of Insurance, Kluwer Academic Publishers, Norwell MA.

Crocker, K. and Snow, A. (1986). 'The efficiency effects of categorical discrimination in the insurance industry', Journal of Political Economy, Vol. 94, pp. 321-344.

Crocker, K. and Snow, A. (2000). 'The theory of risk classification', in Dionne, G. (ed.), Handbook of Insurance, Kluwer Academic Publishers, Norwell MA.

Cummins, J. D., Weiss, M. and Phillips, R. D. (2001). 'The incentive effects of no-fault automobile insurance', Journal of Law and Economics, Vol. 44, pp 427464. 
Cunningham, J., Kernohan, W. And Rush, T. (2006). 'Bed occupancy, turnover intervals and MRSA rates in English hospitals', British Journal of Nursing, Vol. 15, pp. 656-660.

Danzon, P (2000), "Liability for Medical Malpractice" in Culyer, A.J. and Newhouse, J.P. (eds.) Handbook of Health Economics (North-Holland; 2000).

Department of Health (2002). "Getting ahead of the curve: A strategy for combating infectious diseases", Department of Health, London.

Department of Health (2003a). 'Chief Medical Officer. Winning Ways: Working Together to Reduce Healthcare Associated Infection in England', Department of Health, London.

Department of Health (2003b). 'Making Amends: A consultation paper setting out proposals for reforming the approach to clinical negligence in the NHS. A report by the Chief Medical Officer', Department of Health: London.

Department of Health (2006). 'Health Act 2006: Code of Practice for the Prevention and Control of Health Care Associated Infections', Department of Health, London.

Department of Health (2007). 'Hospital organisation, specialty mix and MRSA (ref. 9163)', Department of Health, London

Department of Health (2008). 'Clean, safe care: reducing infections and saving lives', Department of Health, London.

Devlin, R. A. (1992). 'Liability versus no-fault automobile insurance regimes: An analysis of the experience in Quebec', in Dionne, G. (ed.) Contributions to Insurance Economics, Kluwer Academic Publishers, Norwell MA.

Fenn, P., Gray, A. and Rickman, N. (2007). 'Liability, insurance and medical practice', Journal of Health Economics, Vol. 26, pp. 1057-1070.

Fenn, P., Rickman, N., Gray, A. (2004). 'The economics of clinical negligence reform in England', Economic Journal, Vol. 114, pp. F272-F292.

Fenn, P., Gray, A., Rickman, N., Vencappa, D., Rivero, O. and Lotti, E. (2010). 'Enterprise liability, risk pooling and diagnostic care', Journal of Public Administration Research and Theory, Vol. 20, pp. i225-i242.

Grundmann, H., Aanensen, D., van den Wijngaard, C., Spratt, B. and Harmsen, D. (2010). 'Geographic distribution of Staphylococcus aureus causing invasive infections in Europe: A molecular-epidemiological analysis'. PLoS Med 7(1): e1000215. doi:10.1371/journal.pmed.1000215. 
Health Protection Agency (2007). 'Mandatory Surveillance of Healthcare Associated Infections Report 2007', London: Health Protection Agency.

Jackson, Lord R. (2009). 'Review of Civil Litigation Costs: Final Report', The Stationery Office, Norwich.

Johnson A., Pearson A. and Duckworth, G. (2005) 'Surveillance and epidemiology of MRSA bacteraemia in the UK', Journal of Antimicrobial Chemotherapy, Vol. 56, pp. 455-462.

Kennedy, P. (1981). 'Estimation with Correctly Interpreted Dummy Variables in Semilogarithmic Equations', American Economic Review, Vol. 71, p. 801.

Kessler, D. and McClennan, M. (1996). 'Do doctors practice defensive medicine?', Quarterly Journal of Economics, Vol. 111, pp. 353-390.

Kessler, D. and McClellan, M. (2002). 'Medical liability, managed care, and defensive medicine', Journal of Public Economics, Vol. 84, pp. 175-197.

Kochanowski, P. S. \& Young, M. V. (1985). 'Deterrent aspects of no-fault automobile insurance: Some empirical findings', Journal of Risk and Insurance, Vol. 52, pp. 269-288.

Lucet, J., Paoletti, X., Lolom, I., Paugam-Burtz, C., Trouillet, J., Timsit, J., Deblangy, C., Andremont, A. and Regnier B. (2005). 'Successful long-term program for controlling methicillin-resistant Staphylococcus aureus in intensive care units', Intensive Care Medicine, Vol. 31, pp. 1051-1057.

Moore M and Viscusi, W. (1990). Compensating mechanisms for job risks: Wages, Workers' Compensation and Product Liability, Princeton University Press, NJ.

National Audit Office (2000). 'The Management and Control of Hospital Acquired Infection in NHS Acute Trusts in England, HC 230 Session 199900", The Stationery Office, Norwich.

NHSLA (2010). 'NHSLA Risk Management Standards for Acute Trusts Primary Care Trusts and Independent Sector Providers of NHS Care', National Health Service Lituigation Authority, London.

Sloan, F. and Chepke, L. (2008). Medical Malpractice, MIT Press: Cambridge, Mass.

Young, Lord D. (2010). 'Common sense, common safety: A Report by Lord Young of Graffham to the Prime Minister following a Whitehall-wide Review of the Operation of Health and Safety Laws and the Growth of the Compensation Culture', HM Government, London. 


\section{Tables and Figures}

Figure 1. MRSA bacteraemia reports from 2001 to 2008

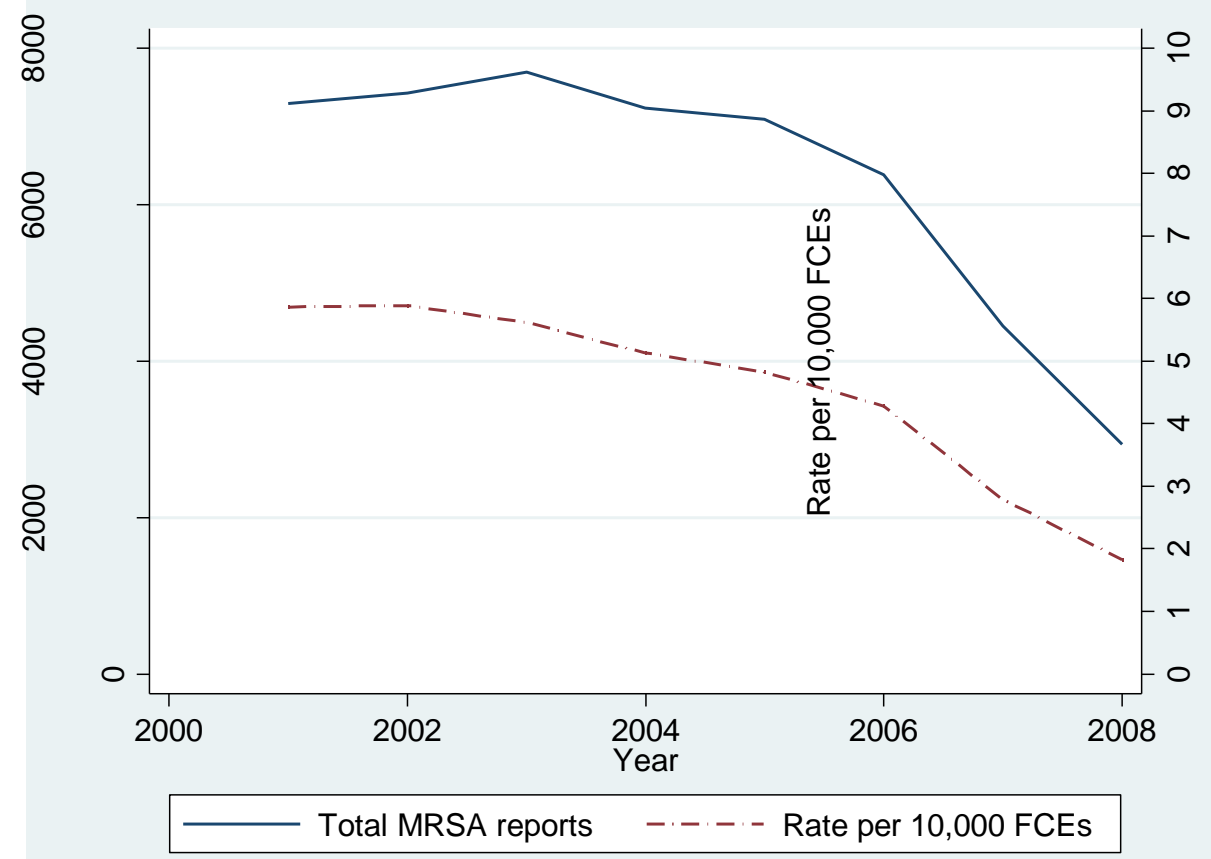

Figure 2. Distributions of annual MRSA infection numbers, NHS acute hospital trusts 2001-2008

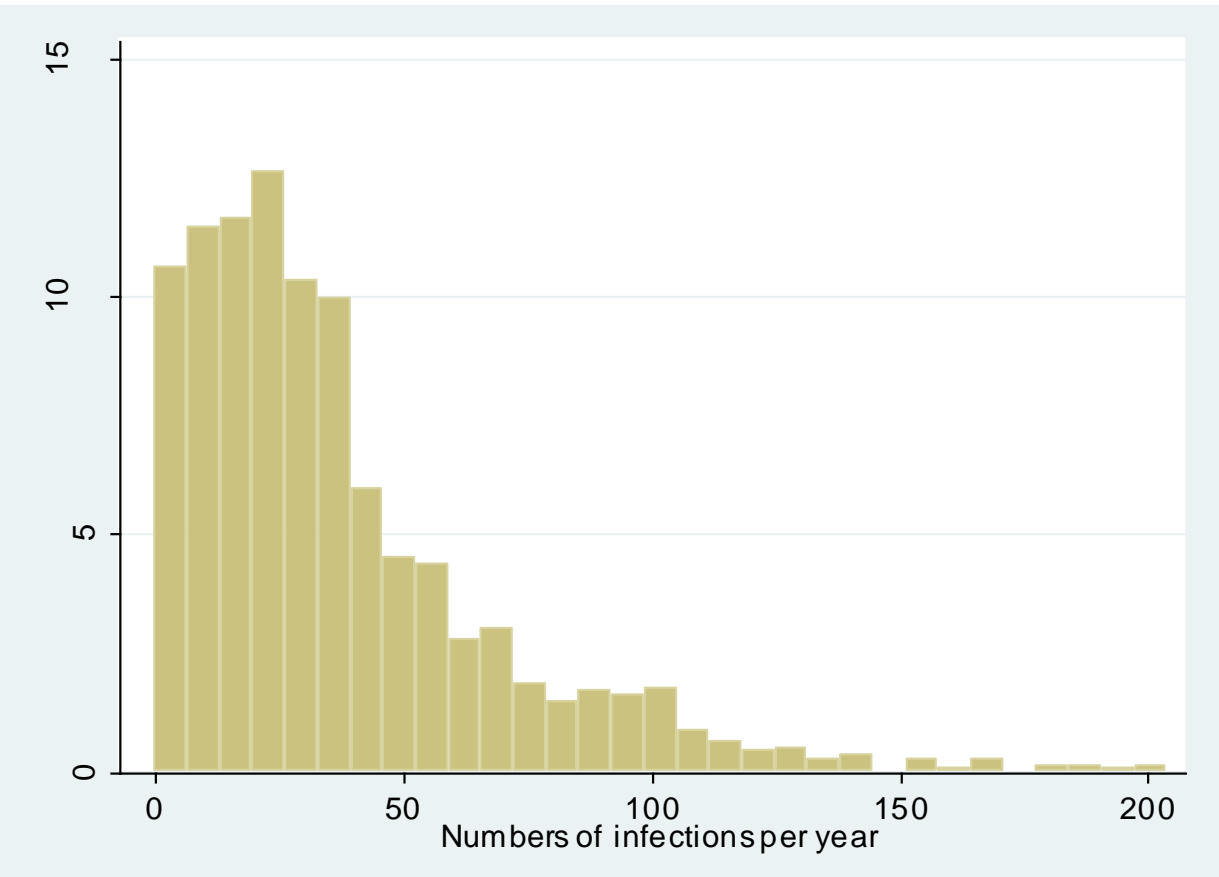


Figure 3. MRSA infection rates by SHA region from 2001 to 2008

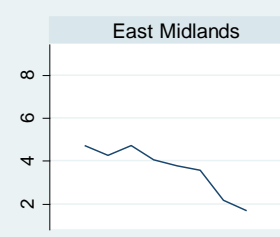

North West

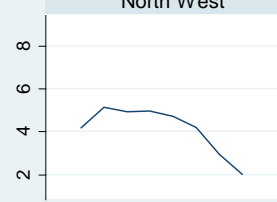

West Midlands

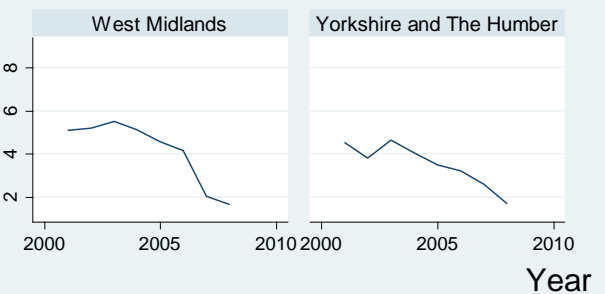

Graphs by sha_final

East of England

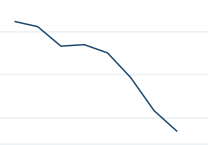

South Central

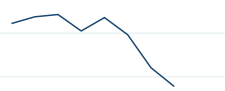

Year
2000

South East Coast

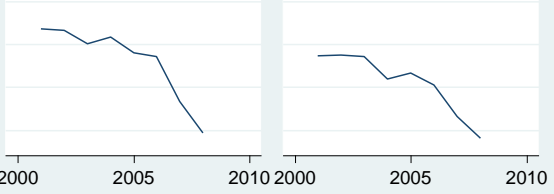

Figure 4. Mean length of stay by SHA region from 2001 to 2008: acute NHS hospital trusts

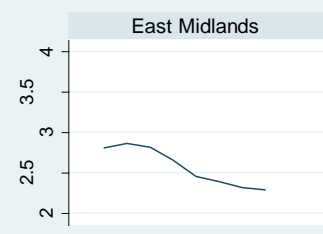

North West
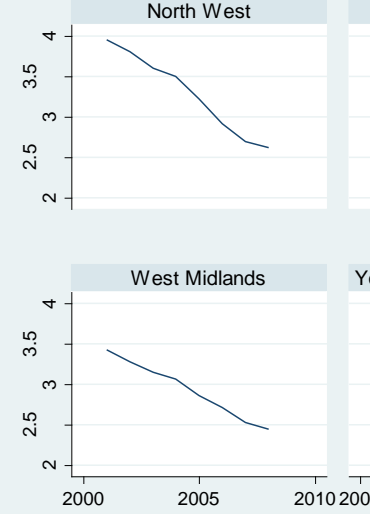

Graphs by sha_final

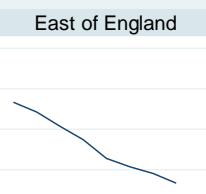

South Central

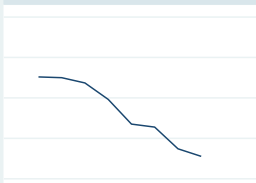

Yorkshire and The Humber

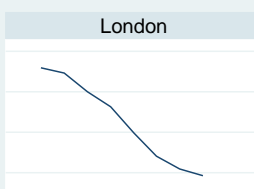

South East Coast

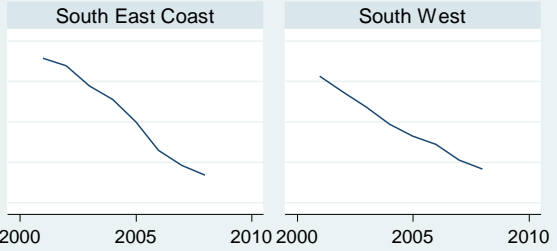

North East

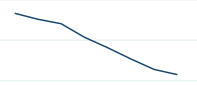

South West

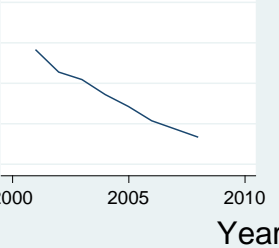

Year 
Figure 5. Mean bed utilisation rates by SHA region from 2001 to 2008: acute NHS hospital trusts

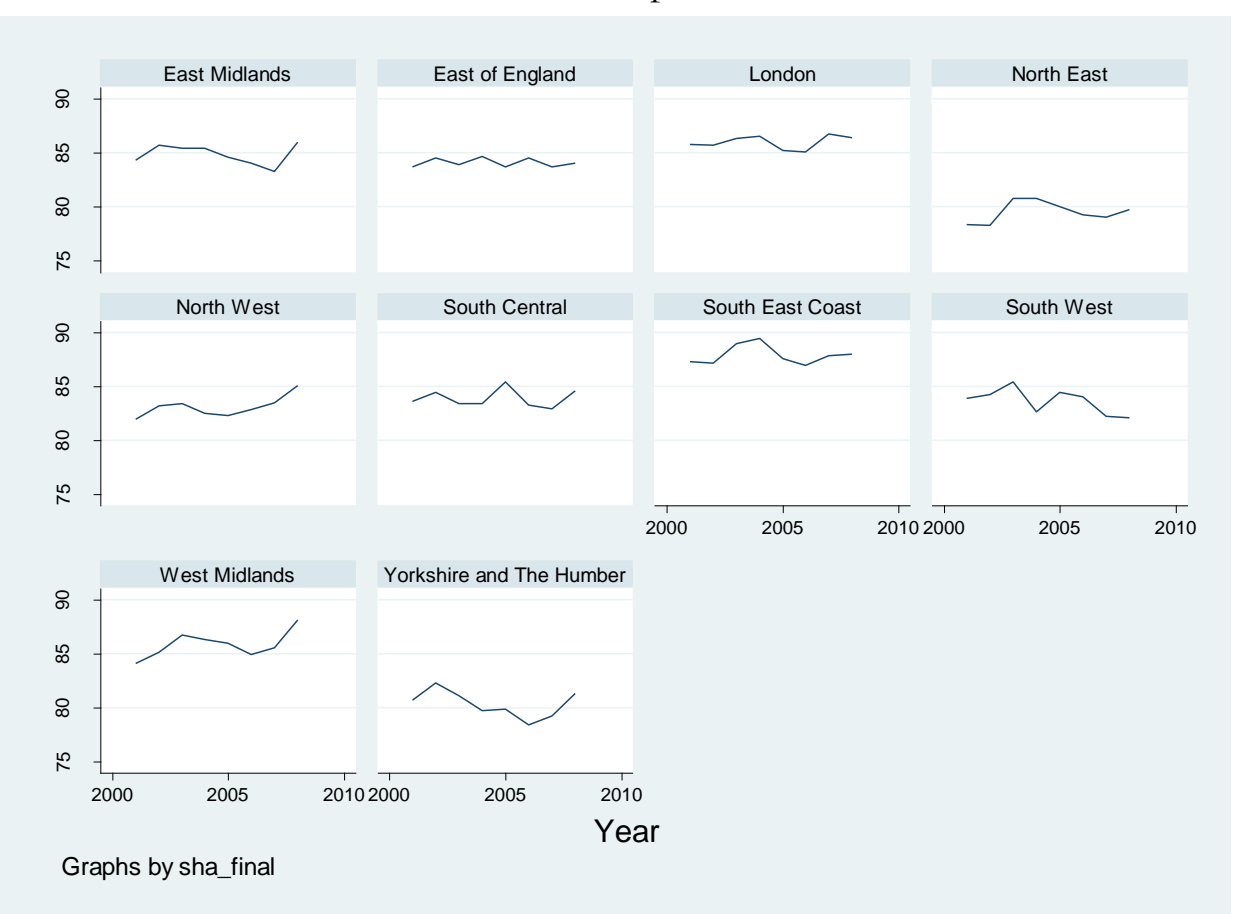


TABLE 1

CNST risk management standards, NHS acute hospital trusts, 2001-2008

\begin{tabular}{lcccccccc}
\hline CNST level & 2001 & 2002 & 2003 & 2004 & 2005 & 2006 & 2007 & 2008 \\
\hline 0 & 20 & 21 & 7 & 0 & 0 & 0 & 2 & 1 \\
1 & 117 & 111 & 115 & 110 & 88 & 88 & 80 & 76 \\
2 & 26 & 29 & 39 & 46 & 68 & 70 & 75 & 76 \\
3 & 1 & 3 & 5 & 10 & 10 & 10 & 12 & 10 \\
Total & 164 & 164 & 166 & 166 & 166 & 168 & 169 & 166 \\
\hline
\end{tabular}

TABLE 2

Mean MRSA infection rates by CNST risk management standard, NHS acute hospital trusts, 2001-2008

\begin{tabular}{lccc}
\hline CNST level & Mean & Std. Dev & N \\
\hline 0 & 6.24 & 3.55 & 64 \\
1 & 4.86 & 2.96 & 779 \\
2 & 3.89 & 2.84 & 356 \\
3 & 2.49 & 1.43 & 50 \\
\hline
\end{tabular}




\section{TABLE 3}

Mean FCEs, bed utilisation rates, length of stay and casemix variables, NHS acute hospital trusts 2001-2008

\begin{tabular}{lrrrrrrrc}
\hline & 2001 & 2002 & 2003 & 2004 & 2005 & 2006 & 2007 & 2008 \\
\hline Finished consultant episodes & 65098 & 70261 & 74359 & 76596 & 80573 & 83632 & 87519 & 92909 \\
Mean length of stay (days) & 3.585 & 3.491 & 3.453 & 3.263 & 2.995 & 2.790 & 2.524 & 2.436 \\
Bed utilisation rate & 0.837 & 0.844 & 0.847 & 0.843 & 0.840 & 0.836 & 0.839 & 0.848 \\
Proportion general medicine & 0.219 & 0.238 & 0.252 & 0.248 & 0.247 & 0.235 & 0.222 & 0.222 \\
Proportion general surgery & 0.097 & 0.103 & 0.105 & 0.104 & 0.104 & 0.102 & 0.101 & 0.099 \\
Proportion gynaecology & 0.033 & 0.035 & 0.035 & 0.033 & 0.033 & 0.034 & 0.035 & 0.033 \\
Proportion obstetrics & 0.035 & 0.036 & 0.038 & 0.038 & 0.038 & 0.038 & 0.035 & 0.035 \\
Proportion paediatrics & 0.068 & 0.070 & 0.071 & 0.068 & 0.074 & 0.074 & 0.080 & 0.079 \\
Proportion trauma/orthopaedics & 0.106 & 0.114 & 0.116 & 0.115 & 0.113 & 0.114 & 0.113 & 0.110 \\
Proportion urology & 0.020 & 0.022 & 0.022 & 0.022 & 0.021 & 0.021 & 0.020 & 0.020 \\
Proportion other surgery32 & 0.062 & 0.065 & 0.066 & 0.066 & 0.064 & 0.065 & 0.067 & 0.069 \\
Proportion other medicine & 0.257 & 0.282 & 0.280 & 0.290 & 0.289 & 0.304 & 0.325 & 0.332 \\
\hline
\end{tabular}

Sources: see Appendix 1.

32 "Other surgery" includes Ear, Nose and Throat (ENT), Ophthalmology, Oral surgery, Restorative dentistry, pediatric dentistry, Orthodontics, Oral and maxillo facial surgery, Endodontics, Periodontics, Prosthodontics, Surgical dentistry, Neurosurgery, Plastic surgery, Cardiothoracic surgery and Paediatric surgery. Many of these are small numbers and not completely consistent over time, hence were grouped under one heading. 
TABLE 4

Mean cleaning costs per bed-day, NHS acute hospital trusts 2001-2008

\begin{tabular}{|c|c|c|c|c|c|c|c|c|}
\hline & 2001 & 2002 & 2003 & 2004 & 2005 & 2006 & 2007 & 2008 \\
\hline $\begin{array}{l}\text { Mean cleaning cost } \\
(\AA)\end{array}$ & 1755761 & 1938495 & 2053049 & 2278236 & 2615390 & 2797186 & 3080852 & 3472303 \\
\hline Mean bed-days & 220905 & 233131 & 236330 & 232298 & 224441 & 219189 & 214776 & 220239 \\
\hline $\begin{array}{l}\text { Mean cleaning cost } \\
\text { per bed-day }(\AA)\end{array}$ & 8.35 & 8.83 & 9.29 & 10.59 & 12.58 & 14.25 & 18.02 & 20.33 \\
\hline
\end{tabular}

Sources: See Appendix 1. 
TABLE 5

Estimation (system GMM)

\begin{tabular}{|c|c|}
\hline & Ln(MRSA infection rate) $[t]$ \\
\hline Ln(MRSA infection rate)[t-1] & $\begin{array}{c}0.172^{* *} \\
(2.80)\end{array}$ \\
\hline Ln(length of stay) & $\begin{array}{c}0.551^{* * * *} \\
(3.86)\end{array}$ \\
\hline $\mathrm{Ln}$ (bed utilization rate) & $\begin{array}{l}-0.397 \\
(-1.28)\end{array}$ \\
\hline Ln(cleaning cost per bedday) & $\begin{array}{l}0.107 \\
(0.75)\end{array}$ \\
\hline CNST level 2 & $\begin{array}{c}-0.0964 \\
(-1.45)\end{array}$ \\
\hline CNST level 3 & $\begin{array}{c}-0.258^{*} \\
(-2.10)\end{array}$ \\
\hline Proportion general surgery & $\begin{array}{c}0.00389 \\
(0.00)\end{array}$ \\
\hline Proportion gynaecology & $\begin{array}{l}-0.108 \\
(-0.13)\end{array}$ \\
\hline Proportion obstetrics & $\begin{array}{l}-0.727 \\
(-1.34)\end{array}$ \\
\hline Proportion paediatrics & $\begin{array}{l}-0.876 \\
(-1.77)\end{array}$ \\
\hline Proportion trauma \& orthopaedics & $\begin{array}{l}-0.129 \\
(-0.42)\end{array}$ \\
\hline Proportion urology & $\begin{array}{l}0.479 \\
(0.21)\end{array}$ \\
\hline Proportion other surgery & $\begin{array}{c}1.162^{* *} \\
(3.02)\end{array}$ \\
\hline Proportion other medicine & $\begin{array}{l}0.307 \\
(1.53)\end{array}$ \\
\hline Year $=2003$ & $\begin{array}{c}0.00944 \\
(0.24)\end{array}$ \\
\hline Year $=2004$ & $\begin{array}{c}-0.0480 \\
(-1.12)\end{array}$ \\
\hline Year $=2005$ & $\begin{array}{c}-0.0417 \\
(-0.66)\end{array}$ \\
\hline Year $=2006$ & $\begin{array}{l}-0.112 \\
(-1.44)\end{array}$ \\
\hline Year $=2007$ & $\begin{array}{c}-0.500 * * * \\
(-5.27)\end{array}$ \\
\hline Year $=2008$ & $\begin{array}{c}-0.877 * * * \\
(-7.97)\end{array}$ \\
\hline Single specialty hospital & $\begin{array}{c}-0.927 * * * \\
(-4.37)\end{array}$ \\
\hline Teaching hospital & $\begin{array}{c}0.0426 \\
(0.69)\end{array}$ \\
\hline East of England & -0.0708 \\
\hline
\end{tabular}




\begin{tabular}{|c|c|}
\hline & $(-0.67)$ \\
\hline London & $\begin{array}{l}0.176 \\
(184)\end{array}$ \\
\hline North East & $\begin{array}{c}-0.0776 \\
(-0.74)\end{array}$ \\
\hline North West & $\begin{array}{c}0.0182 \\
(0.21)\end{array}$ \\
\hline South Central & $\begin{array}{c}-0.0484 \\
(-0.47)\end{array}$ \\
\hline South East & $\begin{array}{l}0.124 \\
(1.20)\end{array}$ \\
\hline South West & $\begin{array}{c}0.00991 \\
(0.09)\end{array}$ \\
\hline West Midlands & $\begin{array}{c}0.198^{*} \\
(2.29)\end{array}$ \\
\hline Yorks \& Humberside & $\begin{array}{l}-0.204 \\
(-1.68)\end{array}$ \\
\hline$N$ & 1058 \\
\hline $\mathrm{N}$ of hospitals & 168 \\
\hline$\chi^{2}$ & 1126.32 \\
\hline $\mathrm{AR}(1)$ test statistic & -5.56 \\
\hline $\mathrm{p}>\mathrm{AR}(1)$ & 0.000 \\
\hline $\mathrm{AR}(2)$ test statistic & 1.36 \\
\hline $\mathrm{p}>\mathrm{AR}(2)$ & 0.173 \\
\hline No. of instruments & 113 \\
\hline Hansen J statistic & 107.92 \\
\hline $\mathrm{p}>\mathrm{J}$ & 0.617 \\
\hline Diff. in Hansen & \\
\hline [Null: CNST levels $2 \& 3$ jointly exogenous] & \\
\hline$\chi^{2}(2)$ & 2.18 \\
\hline $\mathrm{p}>\chi^{2}$ & 0.337 \\
\hline
\end{tabular}




\section{Appendix 1: Data sources}

\begin{tabular}{|c|c|c|}
\hline Variable & Source & Web link \\
\hline MRSA infections & $\begin{array}{l}\text { MRSA Surveillance } \\
\text { System, Department of } \\
\text { Health }\end{array}$ & $\begin{array}{l}\text { http://www.dh.gov.uk/en/Publicationsandstatistics/P } \\
\text { ublications/PublicationsStatistics/DH } 4085951\end{array}$ \\
\hline FCEs; Length of stay & $\begin{array}{l}\text { Hospital Episode } \\
\text { Statistics, Department of } \\
\text { Health }\end{array}$ & $\begin{array}{l}\underline{\text { http://www.hesonline.nhs.uk/Ease/servlet/ContentS }} \\
\underline{\text { erver? siteID=1937\&categoryID }=245}\end{array}$ \\
\hline Bed utilisation rate & $\begin{array}{l}\text { Performance Statistics, } \\
\text { Department of Health }\end{array}$ & $\begin{array}{l}\text { http://www.performance.doh.gov.uk/hospitalactivity } \\
\text { Ldata_requests/beds_open_overnight.htm }\end{array}$ \\
\hline Casemix variables & $\begin{array}{l}\text { Hospital Episode } \\
\text { Statistics by speciality, } \\
\text { Department of Health }\end{array}$ & Specific request from Department of Health \\
\hline $\begin{array}{l}\text { Hospital cleaning } \\
\text { services expenditure }\end{array}$ & $\begin{array}{l}\text { NHS Information } \\
\text { Centre, Hospital Estates } \\
\text { and Facilities Statistics }\end{array}$ & http://www.hefs.ic.nhs.uk/DataFiles.asp \\
\hline $\begin{array}{l}\text { CNST risk management } \\
\text { standards }\end{array}$ & $\begin{array}{l}\text { NHSLA factsheets, } \\
\text { NHSLA }\end{array}$ & http://www.nhsla.co.uk/Publications/ \\
\hline Total claims paid & NHSLA claims database & Specific request to NHSLA \\
\hline
\end{tabular}

